\title{
S Research Square \\ Pre-existing and post-COVID-19 immune responses to SARS-CoV-2 in cancer patients
}

Tatjana Bilich

University Hospital Tübingen, Germany https://orcid.org/0000-0002-8107-0419

Malte Roerden

University Hospital Tübingen, Germany https://orcid.org/0000-0001-7283-9778

Yacine Maringer

University Hospital Tübingen, Germany https://orcid.org/0000-0002-2197-8740

Annika Nelde

University Hospital Tübingen, Germany

Jonas S. Heitmann

University Hospital Tübingen, Germany

Marissa L. Dubbelaar

University Hospital Tübingen, Germany

Andreas Peter

University Hospital Tübingen, Germany

\section{Sebastian Hörber}

University Hospital Tübingen, Germany

Jens Bauer

University Hospital Tübingen, Germany

Jonas Rieth

University Hospital Tübingen, Germany

Marcel Wacker

University Hospital Tübingen, Germany

\section{Fiamma Berner}

Kantonsspital St. Gallen, Switzerland

\section{Lukas Flatz}

University Hospital Tübingen, Germany

\section{Stefanie Held}

University Hospital Bonn, Germany

\section{Peter Brossart}

University Hospital Bonn, Germany

\section{Melanie Märklin}

University Hospital Tübingen, Germany

Hans-Georg Rammensee

University of Tübingen, Germany

Helmut R. Salih https://orcid.org/0000-0001-8504-8481

https://orcid.org/0000-0002-7305-8620

https://orcid.org/0000-0003-3731-2385 
University Hospital Tübingen, Germany https://orcid.org/0000-0002-6719-1847

Juliane S. Walz ( $\sim$ Juliane.Walz@med.uni-tuebingen.de )

University Hospital Tübingen, Germany https://orcid.org/0000-0001-6404-7391

\section{Research Article}

Keywords: SARS-CoV-2, cancer, T cell response, antibody response, COVID-19

Posted Date: February 12th, 2021

DOl: https://doi.org/10.21203/rs.3.rs-237290/v1

License: (c) (i) This work is licensed under a Creative Commons Attribution 4.0 International License. Read Full License 


\section{Abstract}

Cancer patients, in particular patients with hematological malignancies, are at increased risk for critical illness upon COVID-19. We here assessed antibody as well as $\mathrm{CD} 4^{+}$and $\mathrm{CD} 8^{+} \mathrm{T}$ cell responses in unexposed and SARSCoV-2-infected cancer patients to characterize SARS-CoV-2 immunity and to identify immunological parameters contributing to COVID-19 outcome. Unexposed patients with hematological malignancies presented with reduced prevalence of pre-existing SARS-CoV-2 cross-reactive $\mathrm{CD} 4^{+} \mathrm{T}$ cell responses and signs of $\mathrm{T}$ cell exhaustion when compared to solid tumor patients and healthy volunteers. Whereas SARS-CoV-2 antibody responses did not differ between COVID-19 cancer patients and healthy volunteers, intensity, expandability, and diversity of SARS-CoV-2 T cell responses were profoundly reduced in cancer patients, and the latter associated with a severe course of COVID-19. This identifies impaired SARS-CoV-2 T cell immunity as determinant for dismal outcome of COVID-19 in cancer patients.

\section{Introduction}

COVID-19 caused by SARS-CoV-2 coronavirus has become a worldwide pandemic with dramatic socioeconomic consequences (1). The clinical course of SARS-CoV-2 infection is very heterogenic, ranging from completely asymptomatic cases to severe COVID-19 lung disease with high mortality $(2,3)$. Critical illness of COVID-19 predominantly occurs in elderly individuals with medical comorbidities $(2,4,5)$. Several recent studies reported on the increased risk of cancer patients for a more severe course of COVID-19 and examined clinical predictors for mortality (6-9). Patients with hematological malignancies (HM) were identified as one of the groups with poorest outcomes $(6,10)$. Several large-cohort studies are ongoing to better define risk groups such as patients undergoing specific cancer therapies $(7,11)$. The reasons for the overall increased SARS-CoV-2 mortality in cancer patients so far remain ill defined, but mirror experiences with other viral pathogens. In addition to higher susceptibility to infection due to their overall poor health status and coexisting chronic diseases, cancer patients suffer from dysfunctional humoral and cellular immunity due to both, the disease itself and its treatment $(12,13)$. On the other hand, some authors have suggested that cancer patients might be "protected" from severe COVID-19 morbidity due to their impaired ability to mount inflammatory immune responses $(14,15)$. As of now, data on immune responses and immunity to SARS-CoV-2 in cancer patients are very limited. Two recent studies reported IgG antibody responses in $88 \%$ and $67 \%$ in acute myeloid leukemia (AML) and chronic lymphocytic leukemia (CLL) patients suffering from COVID-19, respectively $(16,17)$. To date, no data are available on SARSCoV-2-directed T cell responses in cancer patients. In the meantime, multiple studies have identified the central role of SARS-CoV-2-specific T cell responses for the clinical course of COVID-19 as well as for the development of long-term immunity (18-25). This comprises evidence for potential pre-existing immunity mediated by $\mathrm{T}$ cells cross-reactive to human common cold coronaviruses $(\mathrm{HCoV})$, which may provide a certain degree of protection against severe illness upon COVID-19 $(18,19,21)$. We here conducted the first characterization of SARS-CoV-2specific and cross-reactive T cell and antibody responses in unexposed and SARS-CoV-2-infected cancer patients. We report a reduced prevalence of pre-existing, cross-reactive $T$ cell responses particularly in unexposed patients with hematological malignancies. Additionally, and in contrast to antibody responses, a reduced intensity, expandability and diversity of T cell responses in cancer patients infected with SARS-CoV-2 was observed, with the latter being associated with severe course of COVID-19. 


\section{Results}

\section{Cancer patient cohort}

SARS-CoV-2 immune responses were characterized in cancer patients never exposed to SARS-CoV-2 (cancer-PRE group, $\mathrm{n}=199$, samples collected prior to SARS-CoV-2 pandemic, Table 1) and in cancer patients with proven SARS-CoV-2 infection (cancer-SARS group, $n=17$, Table 2). PRE and SARS groups comprised patients with various hematological (HM-PRE, $n=101$, HM-SARS $n=8$ ) and solid tumor entities (solid-PRE, $n=98$, solid-SARS $\mathrm{n}=9)$ at different stages and time points during disease undergoing/after diverse anti-cancer treatments (Supplementary Tables S1 and S2). SARS patients presented with a range of asymptomatic or mild (nonhospitalized $n=10$ ) to moderate and severe (hospitalized $n=7$ ) COVID-19 cases (Supplementary Table S2). To delineate particularities in SARS-CoV-2 immune responses in cancer patients, previously described reference groups of non-cancer SARS-CoV-2 convalescent (HV-SARS $n=193$ ) and unexposed healthy individuals (HV-PRE $\mathrm{n}=94$ ) were used for comparison (25).

\section{Cross-reactive SARS-CoV-2 T cell responses in unexposed cancer patients}

To allow for standardized evaluation and determination of pre-existing SARS-CoV-2 T cell responses in unexposed cancer patients (cancer-PRE), we employed broadly applicable human leukocyte antigens (HLA) class I and HLA-DR SARS-CoV-2 epitope compositions (EC). These comprised SARS-CoV-2 cross-reactive CD4 ${ }^{+}$ and $\mathrm{CD}^{+} \mathrm{T}$ cell epitopes recognized by both convalescents and individuals never exposed to SARS-CoV-2 (Supplementary Table S3), as described previously (25). Of the unexposed cancer patients, $11.0 \%$ and $55.6 \%$ showed pre-existing, cross-reactive T cell responses to SARS-CoV-2 HLA class I and HLA-DR cross-reactive EC, respectively, as assessed by IFN-g enzyme-linked immunospot (ELISPOT) assays after 12-day in vitro expansion (Fig. 1A-D). While the recognition frequency of the HLA class I cross-reactive EC in unexposed cancer patients was comparable to the HV-PRE group (11.0\% vs. $16.0 \%$, Fig. $1 \mathrm{C})$, the frequency of pre-existing $\mathrm{T}$ cell responses to the HLA-DR cross-reactive EC was significantly reduced in cancer patients (55.6\% vs. $77.7 \%$, Fig. 1D). Separate examination of cases with solid and hematological malignancies revealed a markedly reduced frequency of cross-reactive $\mathrm{CD}^{+}{ }^{+} \mathrm{T}$ cell responses in patients with $\mathrm{HM}$ compared to both solid tumor patients and HV (34.3\% vs. 77.3\% and 77.7\%, respectively, Fig. 1D). The entities with the lowest detection frequency of pre-existing $\mathrm{T}$ cell responses were myelodysplastic syndromes (MDS, 0.0\%), myeloproliferative neoplasms (MPN, $0.0 \%), C L L(0.0 \%)$, and acute leukemias (AML and acute lymphoblastic leukemia (ALL), 6.3\%, Fig. 1E) for HLA class I as well as MDS (0.0\%), chronic myeloid leukemias (CML, 14.3\%), MPN (16.7\%), and CLL (23.3\%) in case of HLA-DR (Fig. 1F). Univariate regression analysis revealed diagnosis of multiple myeloma (MM), CLL, MPN, and $C M L$ as negative predictors for pre-existing, cross-reactive T cell responses to HLA-DR EC within HM (Supplementary Fig. S1). Demographics (age and gender) and other clinical data of unexposed cancer patients were not identified as predictors of cross-reactive SARS-CoV-2 T cell responses (Supplementary Fig. S1).

In contrast to the decreased frequency of cross-reactive CD $4^{+} \mathrm{T}$ cell responses in cancer patients, the intensity (spot counts per $5 \times 10^{5}$ cells, ELISPOT assays after 12-day in vitro expansion) of pre-existing $T$ cell responses was not significantly reduced for HLA-DR-directed responses (Fig. $1 \mathrm{H}$ ) and even shows a trend to increase for HLA class I responses (Fig. 1G) in unexposed cancer patients compared to HV.

\section{Phenotyping of cross-reactive SARS-CoV-2 T cells and overall T cell function in cancer patients}


Characterization of cross-reactive T cells in unexposed cancer patients using ex vivo flow cytometry-based assessment of surface markers and intracellular cytokine staining (ICS) revealed that $T$ cell responses to the HLA class I cross-reactive EC were mediated by $C D 8^{+} T$ cells, with $1 / 3$ of patients showing an additional $C D 4^{+} T$ cell response. $T$ cell responses to HLA-DR cross-reactive EC were predominantly mediated by $\mathrm{CD} 4^{+} \mathrm{T}$ cells, with $4 / 40(10 \%)$ displaying an additional CD8 ${ }^{+} \mathrm{T}$ cell response (Fig. 2A). The vast majority of cross-reactive $\mathrm{CD} 4^{+}$and $\mathrm{CD} 8^{+} \mathrm{T}$ cells were multi-functional, with positivity for several of the markers interleukin 2 (IL-2), tumor necrosis factor (TNF), interferon-g (IFN-g), and CD107a (Fig. 2B, Supplementary Fig. S2).

To put the frequency and intensity of cross-reactive SARS-CoV-2 T cell responses in the broader context of antigen-specific $T$ cell recognition in cancer patients, we compared pre-existing SARS-CoV-2 T cell responses with anti-viral immune responses to HLA class I and HLA-DR peptide panels (including Epstein-Barr virus (EBV), cytomegalovirus (CMV), and adenovirus (ADV) peptides (Supplementary Table S3). Compared to cross-reactive SARS-CoV-2 recognition, $\mathrm{T}$ cell responses to other chronic and past viral infections were more frequent in cancer patients ( $72.9 \%$ vs. $11.0 \%$ and $64.3 \%$ vs. $55.6 \%$ for HLA class I and HLA-DR, respectively). Concordance of T cell responses to HLA class I and HLA-DR cross-reactive SARS-CoV-2 T cell epitopes with recognition of other viral peptide panels was shown in 12/64 (18.8\%) and 59/99 (59.6\%) of HM patients and 10/81 (12.3\%) and 63/97 (64.9\%) of solid tumor patients, respectively (Fig. 2C). A correlation between T cell responses to HLA-DR SARSCoV-2 cross-reactive EC and the HLA-DR viral peptide panel was observed (Fig. 2C, Pearson's R=0.22, $p=$ $0.002)$.

\section{$\mathrm{CD}^{+} \mathrm{T}$ cells of patients with $\mathrm{HM}$ show patterns of exhaustion}

To uncover the reasons underlying the reduced frequency of pre-existing SARS-CoV- 2 cross-reactive $C D 4^{+} T$ cell responses in patients with HM, we comparatively analyzed a panel of exhaustion markers (PD-1, CTLA-4, LAG-3, TIM-3) in $C D 8^{+}$and $C D 4^{+}$T cells in unexposed HM $(n=11)$, solid tumor patients $(n=10)$, and HV $(n=9$, Fig. 2D and $\mathrm{E}$ ). Interestingly, and in contrast to $\mathrm{CD} 8^{+} \mathrm{T}$ cells from solid tumor and $\mathrm{HM}$ as well as $\mathrm{CD} 4^{+} \mathrm{T}$ cells from solid tumors a clear pattern of exhaustion was observed for $\mathrm{CD} 4^{+} \mathrm{T}$ cells of $\mathrm{HM}$ patients, with a profoundly higher proportion of T cells expressing PD-1, LAG-3, and TIM-3 when compared to HV (Fig. 2E). Exhaustion of CD $4^{+} \mathrm{T}$ cells may thus explain the observed reduction of pre-existing cross-reactive HLA-DR SARS-CoV-2 T cell responses in $\mathrm{HM}$.

\section{Antibody and T cell responses to SARS-CoV-2 in cancer patients suffering from COVID-19}

Two independent assays were employed to assess SARS-CoV-2 antibody responses in cancer patients with proven SARS-CoV-2 infection (cancer-SARS, $n=16$, Table 2) and in non-cancer SARS-CoV-2 convalescents (HVSARS, $n=193$ ) to determine (i) ratios of IgG and IgA antibodies targeting the $S 1$ domain of the spike protein including the immunologically relevant receptor binding domain (RBD, EUROIMMUN; Fig. 3A and B) as well as (ii) anti-nucleocapsid antibody titers (Elecsys ${ }^{\circledR}$ immunoassay including lgG; Fig. 3C). Excluding borderline responses, 10/14 (71.4\%), 11/16 (68.8\%) and 14/16 (87.5\%) of SARS cancer patients showed positive anti-S1 $\lg G$ and $\lg A$ and anti-nucleocapsid antibody responses, respectively. Neither antibody positivity rate nor antibody ratio or titer differed between cancer and HV convalescents, nor between solid tumor and HM patients (Fig. 3AC). In line with previous reports (25-27), increased anti-S1 IgG ratios were observed in cancer patients with a 
more severe course of COVID-19 requiring hospitalization and/or SARS-CoV-2 treatment, but did not reach the level of statistical significance due to the small sample size (Fig. 3D).

Next, we aimed to enable standardized analyses of SARS-CoV-2 T cell responses in COVID-19 cancer patients. To this end we applied SARS-CoV-2-specific EC recognized exclusively in COVID-19 convalescents in addition to the above described HLA class I and HLA-DR SARS-CoV-2 cross-reactive EC (Supplementary Table S3), as described previously (25). Out of 17 SARS cancer patients, 14 (82.4\%) showed T cell responses to at least one of the HLA class I and HLA-DR specific or cross-reactive EC, as assessed by ex vivo IFN-g ELISPOT assays (Fig. 3E-G, Supplementary Fig. S3A and B, Supplementary Table S2). Whereas no significant difference in the recognition frequency of T cell responses to the SARS-CoV-2-specific HLA class I and HLA-DR EC was observed, the frequency of $T$ cell responses to the HLA-DR cross-reactive EC was significantly reduced in cancer patients compared to HV (58.8\% vs. 86.6\%, Fig. 3F and G, Supplementary Fig. S3A and B). Alike in unexposed cancer patients (cancer-PRE), separate analysis for solid and hematological neoplasms revealed that this was due to the markedly reduced frequency of cross-reactive $\mathrm{CD} 4^{+} \mathrm{T}$ cell responses in patients with $\mathrm{HM}$ compared to solid tumor patients and HV (Supplementary Fig. S3B).

In contrast to unexposed donors (PRE group), the intensity (spot counts per $5 \times 10^{5}$ cells) of T cell responses to HLA-DR SARS-CoV-2-specific EC was significantly lower in SARS cancer patients compared to HV (Fig. 3I). A similar trend was observed for $T$ cell responses to the HLA-DR cross-reactive EC (Supplementary Fig. S3D). No statistically significant differences were observed with regard to the intensities of $\mathrm{HV}$ and cancer patient $\mathrm{T}$ cell responses to HLA class I cross-reactive and SARS-CoV-2-specific EC (Fig. 3H, Supplementary Fig. S3C).

\section{Reduced expandability and diversity of SARS-CoV-2 CD4 ${ }^{+} \mathrm{T}$ cell responses in cancer patients with COVID-19}

To better characterize SARS-CoV-2 T cell responses in cancer patients, we investigated pre-existing and postinfectious SARS-CoV-2 T cell responses in a patient with squamous cell laryngeal carcinoma (UPN317, 62 years, Supplementary Fig. S4). Pre-existing SARS-CoV-2 T cell responses to HLA class I and HLA-DR EC were neither detected directly ex vivo (Supplementary Fig. S4A) nor after 12-day in vitro expansion (data not shown). PostCOVID-19 CD $4^{+}$and CD8 ${ }^{+}$T cells of the patient showed high expression of the exhaustion marker CTLA-4 (Supplementary Fig. S4). De novo SARS-CoV-2 CD4 ${ }^{+} \mathrm{T}$ cell responses to HLA-DR specific and cross-reactive EC were detected 18 days after confirmation of infection (Supplementary Fig. 4). Single epitope mapping using 20 validated HLA-DR T cell epitopes (binding to several HLA-DR allotypes, derived from multiple open-reading frames, Supplementary Table S3, as described previously (25)) after 12-day in vitro expansion revealed recognition of only one HLA-DR SARS-CoV-2 T cell epitope, indicative of reduced expandability and diversity of the patients T cells upon infection (Supplementary Fig. S4). To expand on this observation, we analyzed recognition frequencies and intensities of SARS-CoV-2 T cell responses to our 20 HLA-DR T cell epitopes in the SARS cancer cohort ( $n=17$, Fig. 4A). We observed T cell responses against 15/20 (75\%) of these HLA-DR single T cell epitopes in the SARS cancer cohort. T cell response intensity after in vitro 12-day expansion, as a measure

of expandability of SARS-CoV-2 T cells, showed high inter-individual and inter-peptide heterogeneity (Fig. 4B). Of note, for $73.3 \%(11 / 15)$ of SARS-CoV-2 HLA-DR peptides reduced intensity of SARS-CoV-2 T cell responses after in vitro expansion was observed in SARS cancer patients compared to HV, reaching the level of significance for 5/15 peptides (Fig. 4B). Patterns of T cell phenotypes and functionality of SARS-CoV-2 T cell responses were comparable between SARS and unexposed cancer patients (Supplementary Fig. S5). 
Most importantly, the diversity of SARS-CoV-2 CD4 ${ }^{+} \mathrm{T}$ cell responses $-i$.e. the recognition of multiple different T cell epitopes implicated as prerequisite for effective immunity $(25,28)$ - was significantly reduced in cancer patients compared to HV, with the most pronounced impairment observed in patients with HM (median percentage of recognized peptides in cancer-SARS and HM-SARS vs. HV-SARS, $25 \%$ and $20 \%$ vs. $50 \%$, respectively; $p=0.009$; Fig. $4 \mathrm{C}$ ). Alike in non-cancer convalescent donors (25), reduced T cell response diversity in cancer patients associated with a more severe course of COVID-19 (Fig. 4D), providing evidence that a broad SARS-CoV-2 T cell response is lacking in cancer patients and results in impairment of protective COVID-19 immunity.

\section{Discussion}

Immune control of SARS-CoV-2 has been extensively studied during the COVID-19 pandemic, resulting in the delineation of distinct immune response patterns associated with severity of disease (25-27). We here report on SARS-CoV-2 T cell and antibody responses in unexposed and COVID-19 cancer patients, providing insights in immune control of SARS-CoV-2 and unraveling factors that contribute to critical illness and high mortality of COVID-19 in this vulnerable patient cohort $(2,4-8,10,29-31)$.

Cross-reactivity of T cells for different virus species or even amongst different pathogens is a well-known phenomenon postulated to enable heterologous immunity after exposure to a non-identical pathogen (32-35). This heterologous immunity, facilitated by cross-reactive $T$ cell responses, can mediate both, beneficial and adverse effects $(34,36,37)$. Pre-existing SARS-CoV-2 T cell responses have been described by several groups in up to $81 \%$ of unexposed donors $(25,38-40)$. Sequence and physiochemical similarities as well as comparable affinity of SARS-CoV-2 cross-reactive T cell epitopes to the known human common cold coronaviruses (HCoVOC43, HCoV-229E, HCoV-NL63, and HCoV-HKU1) provide a functional basis for pre-existing SARS-CoV-2 T cell responses $(25,38,40,41)$. Expandable, cross-reactive SARS-CoV-2 T cells are thought to provide for beneficial heterologous immunity in COVID-19, which might contribute to the highly heterogenic course of disease $(42,43)$. We here show that SARS-CoV-2 cross-reactive T cell responses are detectable in unexposed cancer patients. However, compared to HV and solid tumor patients, the detection frequency of cross-reactive CD4 ${ }^{+} \mathrm{T}$ cells was found to be significantly reduced in patients with $\mathrm{HM}$, who amongst cancer patients are at increased risk for severe COVID-19 (6-8,10,30,31). This observation is critical, as previous data on acute and chronic viral infection (44-46) as well as on T cell responses in COVID-19 convalescent and unexposed individuals, have shown that $\mathrm{CD}^{+} \mathrm{T}$ cells play a central role in SARS-CoV-2 immunity. The pathophysiological relevance is mirrored by a higher frequency of SARS-CoV-2 $\mathrm{CD} 4^{+} \mathrm{T}$ cells compared to $\mathrm{CD} 8^{+} \mathrm{T}$ cells detectable in convalescents and unexposed donors as well as an increased $\mathrm{T}$ cell response intensity and a broader cytokine profile of $\mathrm{CD} 4^{+} \mathrm{T}$ cells $(25,47)$.

In the group of unexposed patients with $\mathrm{HM}$, we identified T cell exhaustion as a potential reason for the reduced frequency of SARS-CoV-2 cross-reactive CD4 ${ }^{+} \mathrm{T}$ cells. $\mathrm{T}$ cell exhaustion is a well-described phenomenon in cancer patients, particularly in HM (48-50). T cell exhaustion in HM patients is accompanied by decreased T cell counts and hampered $\mathrm{T}$ cell functionality is mediated by the disease itself as well as by immunosuppressive treatment regimens, resulting in reduced immune control and increased susceptibility to viral infections $(51,52)$. 
Analysis of antibody responses in cancer patients and HV with SARS-CoV-2 infection revealed comparable positivity rates as well as antibody ratios and titers. This is in line with recent findings in CLL and AML patients $(16,17)$, indicative of functional humoral SARS-CoV-2 immunity in these patients. Similar to previous reports in non-cancer COVID-19 patients (25-27), a trend to increased anti-S1 IgG ratios was observed in cancer patients with a more severe course of COVID-19. Even if RBD antibody levels reportedly correspond to virus-neutralizing activity (53), the protective efficacy of the SARS-CoV-2 antibodies detected in the cancer patients remains unclear and needs to be validated in future studies employing neutralizing assays in larger cohorts.

The frequency of T cell responses to specific HLA class I and HLA-DR SARS-CoV-2-specific EC did also not differ between cancer patients and HV. In contrast, the frequency of T cell responses to cross-reactive HLA-DR epitopes was significantly reduced in patients with HM suffering from COVID-19, which might reflect the lack of preexisting SARS-CoV-2 CD $4^{+}$T cells in unexposed HM patients. In contrast to unexposed cancer patients, SARS cancer patients presented with a lower intensity of SARS-CoV-2 T cell responses compared to HV convalescents. This might be explained by the observed impairment of expandability of SARS-CoV-2 T cells in the SARS cancer patient group and is in accordance with the reduced ability of cancer patients to fight viral infections $(51,54,55)$. $T$ cell exhaustion and reduced $T$ cell functionality were also reported for non-cancer patients suffering from severe and critical illness upon COVID-19, and this impairment is observed even prior to the onset of acute respiratory distress syndrome (56). In line with these observations and based on the ability of immune checkpoint inhibition to restore functionality of exhausted T cells allowing to efficiently counteract viral infection $(57,58)$, clinical trials currently examine the efficacy of anti-PD-1 antibody treatment to combat COVID-19 in both, cancer and non-cancer patients (NCT04333914, NCT04268537, NCT04356508, NCT04343144, and NCT04413838).

Previous work on viral diseases including SARS-CoV-2 implicates diversity of T cell responses, i.e. recognition of multiple T cell epitopes, as an important prerequisite for effective immunity $(25,28)$. We here show that diversity of SARS-CoV-2 T cell responses is decreased in COVID-19 cancer patients, particularly in HM. The observed correlation of decreased T cell response diversity with severity of COVID-19 delineates an immunological cause for critical illness and high mortality of COVID-19 in cancer patients.

The relatively small and heterogeneous patient cohort of our study calls for analyses in larger cancer patient cohorts. Nevertheless, this first characterization of SARS-CoV-2 immune responses in unexposed and SARS-CoV2-infected cancer patients has important implications for understanding of the pathophysiology of COVID-19, as well as the selection and development of therapeutic measures and vaccines for this high-risk patient cohorts.

\section{Methods}

\section{Patients and blood samples}

Peripheral blood mononuclear cells (PBMCs) asserted from blood donations of cancer patients were collected prior to the SARS-CoV-2 pandemic (04/2009 - 11/2019) at three centers (University Hospital Tübingen, Germany; University Hospital Bonn, Germany; University Hospital St. Gallen, Switzerland) to assess the prevalence of pre-existing cross-reactive SARS-CoV-2 T cell responses (PRE group, $n=199$ ). 
Blood and serum samples from cancer patients after SARS-CoV-2 infection (SARS group, $\mathrm{n}=17$ ) were collected at the University Hospital Tübingen, Germany from 4/2020 - 12/2020. SARS-CoV-2 infection was confirmed by PCR after nasopharyngeal swab. Sample collection for COVID-19 cancer patients was performed between 14 263 days (median 47 days) after positive PCR. In non-hospitalized patients, donor characteristics and COVID-19 symptoms were assessed by questionnaire. For hospitalized patients, data was obtained from clinical data records.

Informed consent was obtained in accordance with the Declaration of Helsinki protocol. The study was approved by and performed according to the guidelines of the local ethics committees (University of Tübingen: 454/2016/BO2, 406/2019/BO2, 179/2020/BO2; University of Bonn: 266/08; Kantonsspital St. Gallen: Ethikkommission Ostschweiz [EKOS] 16/079).

PBMCs were isolated by density gradient centrifugation. Serum was separated by centrifugation for 10 min and the supernatant was stored at $-80^{\circ} \mathrm{C}$. Detailed cancer patient characteristics are provided in Tables 1 and 2 and Supplementary Tables S1 and S2.

To delineate differences in SARS-CoV-2 immune responses in cancer patients, a reference group of SARS-CoV-2 convalescent and unexposed healthy individuals, described in a previous work, was applied (25). PBMCs of unexposed HV (HV-PRE, $n=94)$ were collected prior to the SARS-CoV-2 pandemic $(06 / 2007-11 / 2019)$. Sample collection for COVID-19 convalescent HV (HV-SARS, $n=193$ ) was performed between 16 - 59 days (median 41 days) after positive PCR.

\section{Peptides}

Synthetic peptides were provided by EMC Microcollections GmbH and INTAVIS Peptide Services GmbH \& Co. KG. The SARS-CoV-2 HLA class I and HLA-DR T cell epitopes as well as the applied epitope compositions (EC) were characterized in detail in a previous work (25) analyzing T cell responses in convalescents after COVID-19 and in healthy donors never exposed to the virus. To standardize analyses of SARS-CoV-2 T cell responses, broadly applicable HLA class I and HLA-DR SARS-CoV-2-specific EC (16 and 5 HLA class I and HLA-DR peptides, respectively) recognized exclusively in COVID-19 convalescents or cross-reactive EC (9 and 10 HLA class I and HLA-DR peptides, respectively) recognized by both, convalescents and individuals never exposed to SARS-CoV-2 (Supplementary Table S3) were used. For the analyses of T cell response diversity, which requires the analysis of multiple peptides, promiscuous SARS-CoV-2 HLA-DR T cell epitopes (20 peptides with multiple HLA-DR restrictions) were used.

HLA class I and HLA-DR viral peptide panels comprising peptides derived from EBV, CMV, and ADV (Supplementary Table S3) were used to assess the general T cell functionality in cancer patients.

\section{IFN-g ELISPOT assay ex vivo or following 12-day in vitro expansion}

For 12-day in vitro expansion, PBMCs were pulsed with HLA class I or HLA-DR peptide pools (1 mg/mL per peptide for HLA class I or $5 \mathrm{mg} / \mathrm{mL}$ for HLA-DR) and cultured for 12 days adding $20 \mathrm{U} / \mathrm{mL}$ IL-2 (Novartis) on days 3, 5, and 7. Peptide-stimulated (in vitro expanded) or freshly thawed (ex vivo) PBMCs were analyzed by IFNg ELISPOT assay as described previously (25). In brief, $2-8 \times 10^{5}$ cells per well were incubated with $1 \mathrm{mg} / \mathrm{mL}$ (HLA class I) or $2.5 \mathrm{mg} / \mathrm{mL}$ (HLA-DR) of EC or single peptides in 96-well ELISPOT plates coated with anti-IFN-g 
antibody (clone 1-D1K, 2 mg/mL, MabTech, Cat\# 3420-3-250, RRID: AB_907283). PHA (Sigma-Aldrich) served as positive control. An irrelevant HLA-matched control peptide (HLA-DR, ETVITVDTKAAGKGK, FLNA_HUMAN $_{1669-1683}$ ) or $10 \%$ dimethyl sulfoxide (DMSO) in double-distilled water $\left(\mathrm{ddH}_{2} \mathrm{O}\right)$ for HLA class I served as negative control. After $24 \mathrm{~h}$ of incubation, spots were revealed with anti-IFN-g biotinylated detection antibody (clone 7-B6-1, 0.3 mg/mL, MabTech, Cat\# 3420-6-250, RRID: AB_907273), ExtrAvidin-Alkaline Phosphatase (1:1,000 dilution, Sigma-Aldrich), and BCIP/NBT (5-bromo-4-chloro-3-indolyl-phosphate/nitro-blue tetrazolium chloride, Sigma-Aldrich). Spots were counted using an ImmunoSpot S5 analyzer (CTL) and T cell responses were considered positive when the mean spot count was $\geq 3$-fold higher than the mean spot count of the negative control. The intensity of T cell responses is depicted as calculated spot counts, which represent the mean spot count of duplicates normalized to $5 \times 10^{5}$ cells minus the normalized mean spot count of the respective negative control. The recognition frequency of $T$ cell responses within groups indicates the percentage of donors recognizing the respective EC or peptide. The diversity of $\mathrm{T}$ cell responses for single donors represents the number of recognized SARS-CoV-2-derived peptides (positive peptides/tested peptides).

\section{Intracellular cytokine and cell surface marker staining}

Peptide-specific T cells were characterized by intracellular cytokine and cell surface marker staining as previously described (25). In brief, PBMCs were incubated with SARS-CoV-2 peptide/EC or negative control peptide, Brefeldin A (Sigma-Aldrich), and GolgiStop (BD Biosciences). Staining was performed using Cytofix/Cytoperm solution (BD), Aqua live/dead (1:400 dilution, Invitrogen), APC/Cy7 anti-human CD4 (1:100 dilution, BioLegend, Cat\# 300518, RRID: AB_314086), PE/Cy7 anti-human CD8 (1:400 dilution, Beckman Coulter, Cat\# 737661, RRID: AB_1575980), Pacific Blue anti-human TNF (1:120 dilution, BioLegend, Cat\# 502920, RRID: AB_528965), FITC anti-human CD107a (1:100 dilution, BioLegend, Cat\# 328606, RRID: AB_1186036), and PE anti-human IFN-g monoclonal antibodies (1:200 dilution, BioLegend, Cat\# 506507, RRID: AB_315440). PMA and ionomycin (Sigma-Aldrich) served as positive control. All samples were analyzed on a FACS Canto II cytometer (BD).

\section{Flow cytometry-based analysis of T cell exhaustion marker expression}

T cell exhaustion was assessed based on cell surface expression of CD279 (PD-1) and CD366 (TIM-3) as well as intracellular expression of CD152 (CTLA-4) and CD223 (LAG-3). Staining was performed using Cytofix/Cytoperm solution (BD), Pacific Blue anti-human CD4 (1:100 dilution, BioLegend, Cat\# 300524, RRID: AB_493099), FITC anti-human CD8 (1:100 dilution, BioLegend, Cat\# 300905, RRID: AB_314908), PE anti-human CD152 (1:50 dilution, BioLegend, Cat\# 349905, RRID: AB_10645522), PE-Cy7 anti-human CD223 (1:100 dilution, BioLegend, Cat\# 369309, RRID: AB_2629752), APC anti-human CD279 (1:100 dilution, BioLegend, Cat\#621609, RRID: AB_2832829), APC/Cy7 anti-human CD366 (1:100 dilution, BioLegend, Cat\# 345025, RRID: AB_2565716). Viable cells were determined using Aqua live/dead (1:400 dilution, Invitrogen). All samples were analyzed on a FACS Canto II cytometer (BD).

\section{SARS-CoV-2 IgG and IgA ELISA (EUROIMMUN)}

SARS-CoV-2 IgG and IgA ELISA (EUROIMMUN) assays were performed as previously described (25) on an automated BEP 2000 Advance® system (Siemens Healthcare Diagnostics GmbH) according to the manufacturer's instructions. The assay detects anti-SARS-CoV-2 IgG and IgA directed against the S1 domain of 
the viral spike protein (including the immunologically relevant receptor binding domain) and relies on an assayspecific calibrator to report a ratio of specimen absorbance to calibrator absorbance. The final interpretation of positivity is determined by the ratio above a threshold value given by the manufacturer: positive (ratio $\geq 1.1$ ), borderline (ratio $0.8-1.0$ ), or negative (ratio < 0.8). Quality control was performed following the manufacturer's instructions on each day of testing.

\section{Elecsys $\AA^{\circledR}$ anti-SARS-CoV-2 immunoassay (Roche Diagnostics GmbH)}

The Elecsys ${ }^{\circledR}$ anti-SARS-CoV-2 ECLIA (electrogenerated chemiluminescence immunoassay) assay was performed as previously described (25). The assay detects high-affinity antibodies (including lgG) directed against the nucleocapsid protein of SARS-CoV-2 in human serum. Readout was performed on a Cobas e411 analyzer. Negative results were defined by a cut-off index of $<1.0$. Quality control was performed following the manufacturer's instructions on each day of testing.

\section{Software and statistical analysis}

Data are displayed as mean with standard deviation (for $n>3$ ), scatter dot plot with mean, box plot as median with $25^{\text {th }}$ or $75^{\text {th }}$ percentiles and $\mathrm{min} / \mathrm{max}$ whiskers. Description of the applied tests used for statistical analysis are provided within the respective figure legends. Continuous data were tested for distribution (Shapiro-Wilk test) and individual groups were tested by use of Wilcoxon, Mann-Whitney U, Kruskal-Wallis test, or Kruskal-Wallis with Dunn's multiple comparisons test, where appropriate. Categorial data were tested by use of Fisher's exact test of Pearson Chi Square test. Univariate logistic regression analysis was performed to assess the predictive value of patient demographics and clinical parameters for SARS-CoV-2 cross-reactive EC recognition. Flow cytometric data was analyzed using FlowJo 10.0.8 (BD). Graphs were plotted using RStudio and GraphPad Prism 9.0.0. Statistical analyses were conducted using GraphPad Prism 9.0.0 and SPSS 26 (IBM) software. $P$ values of $<0.05$ were considered statistically significant.

\section{Authors' Contributions}

Conceptualization: T.B., M.R., J.S.W.; Data curation: T.B., M.R., J.S.H.; Formal analysis: T.B., M.R.; J.S.H.; Funding acquisition: J.S.W.; Investigation: T.B., M.R., Y.M., A.N., J.S.H., A.P., S.H., J.B., J.R., M.W., F.B., L.F., S.H., P.B.; Methodology: T.B., M.R., A.N., J.S.H., H.-G.R., J.S.W.; Project administration: J.S.W.; Resources: A.P., S.H, L.F., H.G.R., H.R.S., J.S.W.; Supervision: H.-G.R., H.R.S., J.S.W.; Visualization: T.B., M.R., M.L.D.; Writing - original draft preparation: T.B., M.R., J.S.W.; Writing - review and editing: T.B., M.R., Y.M., A.N., J.S.H., M.L.D., A.P., S.H., J.B., J.R., M.W., F.B., L.F., S.H., P.B., M.M., H.-G.R., H.R.S., J.S.W.

\section{Declarations}

\section{Statement of significance}

This first comprehensive analysis of SARS-CoV-2 immune responses in cancer patients reports on the implications of impaired SARS-CoV-2 T cell responses for understanding pathophysiology and predicting severity of COVID-19, in turn allowing for the development of therapeutic measures and vaccines for this vulnerable patient population. 


\section{Disclosure of Potential Conflicts of Interest}

Hans-Georg Rammensee is shareholder of Immatics Biotechnologies GmbH and Curevac AG. Tatjana Bilich, Annika Nelde, Hans-Georg Rammensee, and Juliane S. Walz are listed as inventors for patents on peptides described in this manuscript. The other authors declare no potential conflicts of interest.

\section{Acknowledgements}

We thank Ulrike Schmidt, Sabrina Sauter, Hannah Zug, Sabrina Augstein, Celine Reiß, Valentina Agrusa, Michael Beller, Richard Schaad, and Claudia Falkenburger for technical support and project coordination.

This work was supported by the Bundesministerium für Bildung und Forschung (BMBF, FKZ:01KI20130, Juliane S. Walz), the Deutsche Forschungsgemeinschaft (DFG, German Research Foundation, Grant WA 4608/1-2, Juliane S. Walz), the Deutsche Forschungsgemeinschaft under Germany's Excellence Strategy (Grant EXC2180-390900677, Juliane Walz, Helmut Salih, Hans-Georg Rammensee), the German Cancer Consortium (DKTK, Juliane S. Walz, Helmut R. Salih, Hans-Georg Rammensee, Stefan Stevanovic), the Wilhelm Sander Stiftung (Grant 2016.177.2, Juliane S. Walz), the José Carreras Leukämie-Stiftung (Grant DJCLS 05 R/2017, Juliane Walz), and the Fortüne Program of the University of Tübingen (Fortüne number 2451-0-0 and 2581-0-0, Juliane S. Walz and Malte Roerden).

\section{References}

1. Khan S, Siddique R, Shereen MA, Ali A, Liu J, Bai Q, et al. The emergence of a novel coronavirus (SARS-CoV2), their biology and therapeutic options. J Clin Microbiol 2020 doi 10.1128/JCM.00187-20.

2. Zhou F, Yu T, Du R, Fan G, Liu Y, Liu Z, et al. Clinical course and risk factors for mortality of adult inpatients with COVID-19 in Wuhan, China: a retrospective cohort study. The lancet 2020.

3. Young BE, Ong SWX, Kalimuddin S, Low JG, Tan SY, Loh J, et al. Epidemiologic features and clinical course of patients infected with SARS-CoV-2 in Singapore. Jama 2020;323(15):1488-94.

4. Myers LC, Parodi SM, Escobar GJ, Liu VX. Characteristics of hospitalized adults with COVID-19 in an integrated health care system in California. Jama 2020.

5. Richardson S, Hirsch JS, Narasimhan M, Crawford JM, McGinn T, Davidson KW, et al. Presenting characteristics, comorbidities, and outcomes among 5700 patients hospitalized with COVID-19 in the New York City area. Jama 2020.

6. Yang K, Sheng Y, Huang C, Jin Y, Xiong N, Jiang K, et al. Clinical characteristics, outcomes, and risk factors for mortality in patients with cancer and COVID-19 in Hubei, China: a multicentre, retrospective, cohort study. The Lancet Oncology 2020.

7. Rivera DR, Peters S, Panagiotou OA, Shah DP, Kuderer NM, Hsu C-Y, et al. Utilization of COVID-19 treatments and clinical outcomes among patients with cancer: a COVID-19 and Cancer Consortium (CCC19) cohort study. Cancer discovery 2020;10(10):1514-27.

8. Robilotti EV, Babady NE, Mead PA, Rolling T, Perez-Johnston R, Bernardes M, et al. Determinants of COVID19 disease severity in patients with cancer. Nature medicine 2020;26(8):1218-23.

9. Robilotti EV, Babady NE, Mead PA, Rolling T, Perez-Johnston R, Bernardes M, et al. Determinants of COVID19 disease severity in patients with cancer. Nat Med 2020;26(8):1218-23 doi 10.1038/s41591-020-0979-0. 
10. Dai M, Liu D, Liu M, Zhou F, Li G, Chen Z, et al. Patients with cancer appear more vulnerable to SARS-COV-2: a multicenter study during the COVID-19 outbreak. Cancer discovery 2020;10(6):783-91.

11. Lee LY, Cazier JB, Starkey T, Turnbull C, Team UCCMP, Kerr R, et al. COVID-19 mortality in patients with cancer on chemotherapy or other anticancer treatments: a prospective cohort study. The Lancet 2020;395(10241):1919-26.

12. Ms R. Podar K, Breitkreutz I, Richardson PG, Anderson KC. Multiple myeloma. Lancet 2009;374:324-39.

13. Thommen DS, Schumacher TN. T cell dysfunction in cancer. Cancer cell 2018;33(4):547-62.

14. Reda G, Noto A, Cassin R, Zamprogna G, Borella C, Scarfò L, et al. Reply to "CLL and COVID-19 at the Hospital Clinic of Barcelona: an interim report" Analysis of six hematological centers in Lombardy. Leukemia 2020;34(9):2531-2.

15. Treon SP, Castillo J, Skarbnik AP, Soumerai JD, Ghobrial IM, Guerrera ML, et al. The BTK-inhibitor ibrutinib may protect against pulmonary injury in COVID-19 infected patients. Blood 2020.

16. Roeker LE, Knorr DA, Pessin MS, Ramanathan LV, Thompson MC, Leslie LA, et al. Anti-SARS-CoV-2 antibody response in patients with chronic lymphocytic leukemia. Leukemia 2020;34(11):3047-9.

17. O’Nions J, Muir L, Zheng J, Rees-Spear C, Rosa A, Roustan C, et al. SARS-CoV-2 antibody responses in patients with acute leukaemia. Leukemia 2021;35(1):289-92.

18. Grifoni A, Weiskopf D, Ramirez SI, Mateus J, Dan JM, Moderbacher CR, et al. Targets of T Cell Responses to SARS-CoV-2 Coronavirus in Humans with COVID-19 Disease and Unexposed Individuals. Cell 2020;181(7):1489-501 e15 doi 10.1016/j.cell.2020.05.015.

19. Mateus J, Grifoni A, Tarke A, Sidney J, Ramirez SI, Dan JM, et al. Selective and cross-reactive SARS-CoV-2 T cell epitopes in unexposed humans. Science 2020 doi 10.1126/science.abd3871.

20. Weiskopf D, Schmitz KS, Raadsen MP, Grifoni A, Okba NMA, Endeman H, et al. Phenotype and kinetics of SARS-CoV-2-specific T cells in COVID-19 patients with acute respiratory distress syndrome. Sci Immunol 2020;5(48) doi 10.1126/sciimmunol.abd2071.

21. Braun J, Loyal L, Frentsch M, Wendisch D, Georg P, Kurth F, et al. SARS-CoV-2-reactive T cells in healthy donors and patients with COVID-19. Nature 2020 doi 10.1038/s41586-020-2598-9.

22. Le Bert N, Tan AT, Kunasegaran K, Tham CYL, Hafezi M, Chia A, et al. SARS-CoV-2-specific T cell immunity in cases of COVID-19 and SARS, and uninfected controls. Nature 2020;584(7821):457-62 doi 10.1038/s41586020-2550-z.

23. Dan JM, Mateus J, Kato Y, Hastie KM, Yu ED, Faliti CE, et al. Immunological memory to SARS-CoV-2 assessed for up to 8 months after infection. Science 2021:eabf4063 doi 10.1126/science.abf4063.

24. Bilich T, Nelde A, Heitmann JS, Maringer Y, Roerden M, Bauer J, et al. Differential kinetics of T cell and antibody responses delineate dominant T cell epitopes in long-term immunity after COVID-19. Research Square 2020 doi 10.21203/rs.3.rs-114499/v1.

25. Nelde A, Bilich T, Heitmann JS, Maringer Y, Salih HR, Roerden M, et al. SARS-CoV-2-derived peptides define heterologous and COVID-19-induced T cell recognition. Nature immunology 2021;22(1):74-85.

26. Laing AG, Lorenc A, Del Barrio IDM, Das A, Fish M, Monin L, et al. A dynamic COVID-19 immune signature includes associations with poor prognosis. Nature medicine 2020;26(10):1623-35.

27. Chen X, Pan Z, Yue S, Yu F, Zhang J, Yang Y, et al. Disease severity dictates SARS-CoV-2-specific neutralizing antibody responses in COVID-19. Signal transduction and targeted therapy 2020;5(1):1-6. 
28. Yager EJ, Ahmed M, Lanzer K, Randall TD, Woodland DL, Blackman MA. Age-associated decline in T cell repertoire diversity leads to holes in the repertoire and impaired immunity to influenza virus. J Exp Med 2008;205(3):711-23 doi 10.1084/jem.20071140.

29. Passamonti F, Cattaneo C, Arcaini L, Bruna R, Cavo M, Merli F, et al. Clinical characteristics and risk factors associated with COVID-19 severity in patients with haematological malignancies in Italy: a retrospective, multicentre, cohort study. The Lancet Haematology 2020;7(10):e737-e45.

30. Yu J, Ouyang W, Chua ML, Xie C. SARS-CoV-2 transmission in patients with cancer at a tertiary care hospital in Wuhan, China. JAMA oncology 2020.

31. Kuderer NM, Choueiri TK, Shah DP, Shyr Y, Rubinstein SM, Rivera DR, et al. Clinical impact of COVID-19 on patients with cancer (CCC19): a cohort study. The Lancet 2020.

32. Friberg H, Burns L, Woda M, Kalayanarooj S, Endy TP, Stephens HA, et al. Memory CD8+ T cells from naturally acquired primary dengue virus infection are highly cross-reactive. Immunol Cell Biol 2011;89(1):122-9 doi 10.1038/icb.2010.61.

33. Su LF, Kidd BA, Han A, Kotzin JJ, Davis MM. Virus-specific CD4(+) memory-phenotype T cells are abundant in unexposed adults. Immunity 2013;38(2):373-83 doi 10.1016/j.immuni.2012.10.021.

34. Petrova G, Ferrante A, Gorski J. Cross-reactivity of T cells and its role in the immune system. Crit Rev Immunol 2012;32(4):349-72 doi 10.1615/critrevimmunol.v32.i4.50.

35. Vali B, Tohn R, Cohen MJ, Sakhdari A, Sheth PM, Yue FY, et al. Characterization of cross-reactive CD8+ T-cell recognition of HLA-A2-restricted HIV-Gag (SLYNTVATL) and HCV-NS5b (ALYDVVSKL) epitopes in individuals infected with human immunodeficiency and hepatitis C viruses. J Virol 2011;85(1):254-63 doi 10.1128/JVI.01743-10.

36. Welsh RM, Che JW, Brehm MA, Selin LK. Heterologous immunity between viruses. Immunol Rev 2010;235(1):244-66 doi 10.1111/j.0105-2896.2010.00897.x.

37. Watkin LB, Mishra R, Gil A, Aslan N, Ghersi D, Luzuriaga K, et al. Unique influenza A cross-reactive memory CD8 T-cell receptor repertoire has a potential to protect against EBV seroconversion. J Allergy Clin Immunol 2017;140(4):1206-10 doi 10.1016/j.jaci.2017.05.037.

38. Braun J, Loyal L, Frentsch M, Wendisch D, Georg P, Kurth F, et al. SARS-CoV-2-reactive T cells in healthy donors and patients with COVID-19. Nature 2020;587(7833):270-4.

39. Le Bert N, Tan AT, Kunasegaran K, Tham CY, Hafezi M, Chia A, et al. SARS-CoV-2-specific T cell immunity in cases of COVID-19 and SARS, and uninfected controls. Nature 2020;584(7821):457-62.

40. Grifoni A, Weiskopf D, Ramirez SI, Mateus J, Dan JM, Moderbacher CR, et al. Targets of T cell responses to SARS-CoV-2 coronavirus in humans with COVID-19 disease and unexposed individuals. Cell 2020;181(7):1489-501. e15.

41. Mateus J, Grifoni A, Tarke A, Sidney J, Ramirez SI, Dan JM, et al. Selective and cross-reactive SARS-CoV-2 T cell epitopes in unexposed humans. Science 2020;370(6512):89-94.

42. Lipsitch M, Grad YH, Sette A, Crotty S. Cross-reactive memory T cells and herd immunity to SARS-CoV-2. Nature Reviews Immunology 2020;20(11):709-13.

43. Saletti G, Gerlach T, Jansen JM, Molle A, Elbahesh H, Ludlow M, et al. Older adults lack SARS CoV-2 crossreactive T lymphocytes directed to human coronaviruses OC43 and NL63. Scientific reports 2020;10(1):110. 
44. Wilkinson TM, Li CK, Chui CS, Huang AK, Perkins M, Liebner JC, et al. Preexisting influenza-specific CD4+ T cells correlate with disease protection against influenza challenge in humans. Nat Med 2012;18(2):274-80 doi 10.1038/nm.2612.

45. Zhou M, Xu D, Li X, Li H, Shan M, Tang J, et al. Screening and identification of severe acute respiratory syndrome-associated coronavirus-specific CTL epitopes. J Immunol 2006;177(4):2138-45 doi 10.4049/jimmunol.177.4.2138.

46. Soghoian DZ, Jessen H, Flanders M, Sierra-Davidson K, Cutler S, Pertel T, et al. HIV-specific cytolytic CD4 T cell responses during acute HIV infection predict disease outcome. Sci Transl Med 2012;4(123):123ra25 doi 10.1126/scitransImed.3003165.

47. Sette A, Crotty S. Adaptive Immunity to SARS-CoV-2 and COVID-19. Cell 2021 doi https://doi.org/10.1016/j.cell.2021.01.007.

48. Wherry EJ, Kurachi M. Molecular and cellular insights into T cell exhaustion. Nature Reviews Immunology 2015;15(8):486-99.

49. Yang Z-Z, Grote DM, Ziesmer SC, Niki T, Hirashima M, Novak AJ, et al. IL-12 upregulates TIM-3 expression and induces $T$ cell exhaustion in patients with follicular B cell non-Hodgkin lymphoma. The Journal of clinical investigation 2012;122(4):1271-82.

50. Riches JC, Davies JK, McClanahan F, Fatah R, Iqbal S, Agrawal S, et al. T cells from CLL patients exhibit features of T-cell exhaustion but retain capacity for cytokine production. Blood 2013;121(9):1612-21.

51. Wade JC. Viral infections in patients with hematological malignancies. ASH Education Program Book 2006;2006(1):368-74.

52. Atkins S, He F. Chemotherapy and beyond: infections in the era of old and new treatments for hematologic malignancies. Infectious Disease Clinics 2019;33(2):289-309.

53. Ju B, Zhang Q, Ge J, Wang R, Sun J, Ge X, et al. Human neutralizing antibodies elicited by SARS-CoV-2 infection. Nature 2020;584(7819):115-9 doi 10.1038/s41586-020-2380-z.

54. Falsey AR, Hennessey PA, Formica MA, Cox C, Walsh EE. Respiratory syncytial virus infection in elderly and high-risk adults. New England Journal of Medicine 2005;352(17):1749-59.

55. Lehners N, Tabatabai J, Prifert C, Wedde M, Puthenparambil J, Weissbrich B, et al. Long-term shedding of influenza virus, parainfluenza virus, respiratory syncytial virus and nosocomial epidemiology in patients with hematological disorders. PLoS One 2016;11(2):e0148258.

56. De Biasi S, Meschiari M, Gibellini L, Bellinazzi C, Borella R, Fidanza L, et al. Marked T cell activation, senescence, exhaustion and skewing towards TH17 in patients with COVID-19 pneumonia. Nature communications 2020;11(1):1-17.

57. Wykes MN, Lewin SR. Immune checkpoint blockade in infectious diseases. Nature Reviews Immunology 2018;18(2):91.

58. Gambichler T, Reuther J, Scheel CH, Becker JC. On the use of immune checkpoint inhibitors in patients with viral infections including COVID-19. Journal for ImmunoTherapy of Cancer 2020;8(2).

\section{Tables}

Table 1. Characteristics of SARS-CoV-2 unexposed cancer patients (PRE group) 


\begin{tabular}{|c|c|c|c|c|c|c|c|c|}
\hline & \multicolumn{3}{|c|}{ Demographics } & \multicolumn{5}{|c|}{ Clinical setting } \\
\hline & $\begin{array}{l}\text { Patients } \\
\text { (no. [\%]) }\end{array}$ & $\begin{array}{l}\text { Female } \\
\text { sex } \\
\text { (no. } \\
{[\%] \text { ) }}\end{array}$ & $\begin{array}{l}\text { Median } \\
\text { age } \\
\text { (range) }\end{array}$ & $\begin{array}{l}\text { Diagnosis } \\
\text { (no. [\%]) }\end{array}$ & $\begin{array}{l}\text { Watch } \\
\text { \& wait } \\
\text { (no. } \\
{[\%] \text { ) }}\end{array}$ & $\begin{array}{l}1^{\text {st line }} \\
\text { therapy } \\
\text { (no. } \\
\text { [\%]) }\end{array}$ & $\begin{array}{l}>1^{\text {st }} \\
\text { line } \\
\text { therapy } \\
\text { (no. } \\
\text { [\%]) }\end{array}$ & $\begin{array}{l}\text { Follow- } \\
\text { up } \\
\text { care } \\
\text { (no. } \\
\text { [\%]) }\end{array}$ \\
\hline Total & 199 & $\begin{array}{l}122 \\
(61)\end{array}$ & $\begin{array}{l}64(22- \\
89)\end{array}$ & $102(51)$ & $\begin{array}{l}26 \\
(13)\end{array}$ & $24(12)$ & $37(19)$ & $10(5)$ \\
\hline $\begin{array}{l}\text { Hematological } \\
\text { malignancies }\end{array}$ & $\begin{array}{l}101 \\
(51)\end{array}$ & $41(41)$ & $\begin{array}{l}66(22- \\
89)\end{array}$ & 34 (34) & $\begin{array}{l}26 \\
(26)\end{array}$ & $15(15)$ & $16(16)$ & $10(10)$ \\
\hline$A M L / A L L$ & $21(11)$ & $6(29)$ & $\begin{array}{l}55(22- \\
78)\end{array}$ & $16(76)$ & $0(0)$ & $1(5)$ & $1(5)$ & $3(14)$ \\
\hline$M D S$ & $1(1)$ & $0(0)$ & $63(63)$ & $0(0)$ & $\begin{array}{l}1 \\
(100)\end{array}$ & $0(0)$ & $0(0)$ & $0(0)$ \\
\hline$C L L$ & $30(15)$ & $11(37)$ & $\begin{array}{l}58(46- \\
69)\end{array}$ & $1(3)$ & $\begin{array}{l}19 \\
(63)\end{array}$ & $7(23)$ & $1(3)$ & $2(7)$ \\
\hline$M M$ & $19(10)$ & $10(53)$ & $\begin{array}{l}70(40- \\
89)\end{array}$ & $6(32)$ & $0(0)$ & $0(0)$ & $13(68)$ & $0(0)$ \\
\hline MGUS & $4(2)$ & $3(75)$ & $\begin{array}{l}72(44- \\
82)\end{array}$ & $0(0)$ & $\begin{array}{l}4 \\
(100)\end{array}$ & $0(0)$ & $0(0)$ & $0(0)$ \\
\hline$C M L$ & $9(5)$ & $3(33)$ & $\begin{array}{l}71(59- \\
80)\end{array}$ & $6(67)$ & $0(0)$ & $3(33)$ & $0(0)$ & $0(0)$ \\
\hline$M P N$ & $12(6)$ & $6(50)$ & $\begin{array}{l}65(39- \\
85)\end{array}$ & $1(8)$ & $2(17)$ & $4(33)$ & $1(8)$ & $4(33)$ \\
\hline Others & $5(3)$ & $2(40)$ & $\begin{array}{l}60(39- \\
78)\end{array}$ & $4(80)$ & $0(0)$ & $1(20)$ & $0(0)$ & $0(0)$ \\
\hline $\begin{array}{l}\text { Solid } \\
\text { malignancies }\end{array}$ & $98(49)$ & $81(83)$ & $\begin{array}{l}64(23- \\
85)\end{array}$ & $68(65)$ & $0(0)$ & $9(9)$ & $21(21)$ & $0(0)$ \\
\hline $\mathrm{OvCa}$ & 67 (34) & $\begin{array}{l}67 \\
(100)\end{array}$ & $\begin{array}{l}61(24- \\
84)\end{array}$ & $62(93)$ & $0(0)$ & $0(0)$ & $5(8)$ & $0(0)$ \\
\hline$N S C L C$ & $20(10)$ & $6(30)$ & $\begin{array}{l}68(53- \\
85)\end{array}$ & $0(0)$ & $0(0)$ & 7 (35) & $13(65)$ & $0(0)$ \\
\hline Others & $11(6)$ & $8(73)$ & $\begin{array}{l}62(23- \\
80)\end{array}$ & $6(55)$ & $0(0)$ & $2(18)$ & $3(27)$ & $0(0)$ \\
\hline
\end{tabular}

Abbreviations: no., number; AML, acute myeloid leukemia; ALL, acute lymphoblastic leukemia; MDS, myelodysplastic syndrome; CLL, chronic lymphocytic leukemia; MM, multiple myeloma; MGUS, monoclonal gammopathy of undetermined significance; CML, chronic myeloid leukemia; MPN, myeloproliferative neoplasm; OvCa, ovarian carcinoma; NSCLC, non-small cell lung cancer. 
Table 2. Characteristics COVID-19 convalescent cancer patients (SARS group)

\begin{tabular}{|c|c|c|c|c|c|c|c|c|}
\hline & \multicolumn{3}{|c|}{ Demographics } & \multicolumn{5}{|c|}{ Clinical setting } \\
\hline & $\begin{array}{l}\text { Patients } \\
\text { (no. [\%]) }\end{array}$ & $\begin{array}{l}\text { Female } \\
\text { sex } \\
\text { (no. } \\
{[\%] \text { ) }}\end{array}$ & $\begin{array}{l}\text { Median } \\
\text { age } \\
\text { (range) }\end{array}$ & $\begin{array}{l}\text { Diagnosis } \\
\text { (no. [\%]) }\end{array}$ & $\begin{array}{l}1^{\text {st line }} \\
\text { therapy } \\
\text { (no. } \\
{[\%] \text { ) }}\end{array}$ & $\begin{array}{l}>1^{\text {st }} \\
\text { line } \\
\text { therapy } \\
\text { (no. } \\
\text { [\%]) }\end{array}$ & $\begin{array}{l}\text { Follow- } \\
\text { up } \\
\text { care } \\
\text { (no. } \\
{[\%] \text { ) }}\end{array}$ & $\begin{array}{l}\text { Follow- } \\
\text { up } \\
\text { care } \\
\text { after } \\
\text { allo- } \\
\text { HSCT } \\
\text { (no. } \\
[\%])\end{array}$ \\
\hline Total & 17 & $9(53)$ & $\begin{array}{l}58(25- \\
77)\end{array}$ & $0(0)$ & $2(12)$ & $2(12)$ & $9(53)$ & $4(24)$ \\
\hline $\begin{array}{l}\text { Hematological } \\
\text { malignancies }\end{array}$ & $8(47)$ & $4(50)$ & $\begin{array}{l}60(32- \\
68)\end{array}$ & $0(0)$ & 1 (13) & 1 (13) & $2(25)$ & $4(50)$ \\
\hline$A M L$ & $3(18)$ & 1 (33) & $\begin{array}{l}55(32- \\
66)\end{array}$ & $0(0)$ & 1 (33) & $0(0)$ & $0(0)$ & $2(67)$ \\
\hline$B-N H L$ & $2(12)$ & $2(100)$ & $\begin{array}{l}61(53- \\
68)\end{array}$ & $0(0)$ & $0(0)$ & $0(0)$ & $2(100)$ & $0(0)$ \\
\hline Other & $3(18)$ & $1(33)$ & $\begin{array}{l}65(58- \\
77)\end{array}$ & $0(0)$ & $0(0)$ & $1(33)$ & $0(0)$ & $2(67)$ \\
\hline $\begin{array}{l}\text { Solid } \\
\text { malignancies }\end{array}$ & $9(53)$ & $6(67)$ & $\begin{array}{l}56(25- \\
66)\end{array}$ & $0(0)$ & $1(11)$ & $1(11)$ & $7(78)$ & $0(0)$ \\
\hline Breast Cancer & $4(24)$ & $4(100)$ & $\begin{array}{l}55(46- \\
58)\end{array}$ & $0(0)$ & $0(0)$ & $0(0)$ & $4(100)$ & $0(0)$ \\
\hline $\begin{array}{l}\text { Urological } \\
\text { malignancy }\end{array}$ & $2(12)$ & $2(100)$ & $\begin{array}{l}56(46- \\
66)\end{array}$ & $0(0)$ & $1(50)$ & $0(0)$ & $1(50)$ & $0(0)$ \\
\hline Other & $3(18)$ & $2(67)$ & $\begin{array}{l}62(25- \\
65)\end{array}$ & $0(0)$ & $0(0)$ & $1(33)$ & $2(67)$ & $0(0)$ \\
\hline
\end{tabular}

Abbreviations: no., number; allo-HSCT, allogeneic hematopoietic stem cell transplantation; AML, acute myeloid leukemia; B-NHL, B cell Non-Hodgkin lymphoma.

\section{Figures}


A
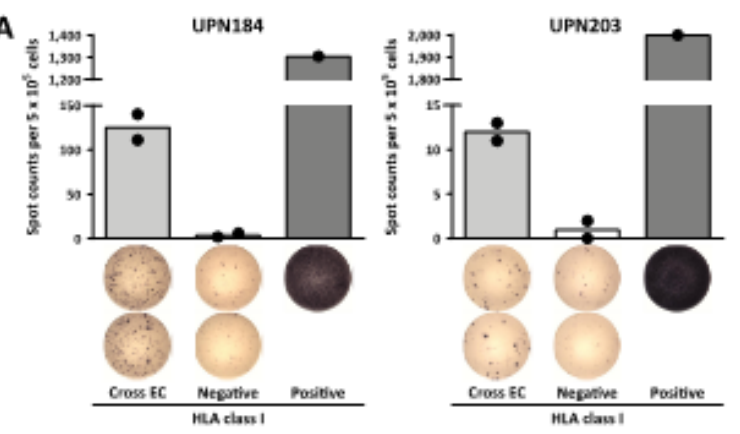

C

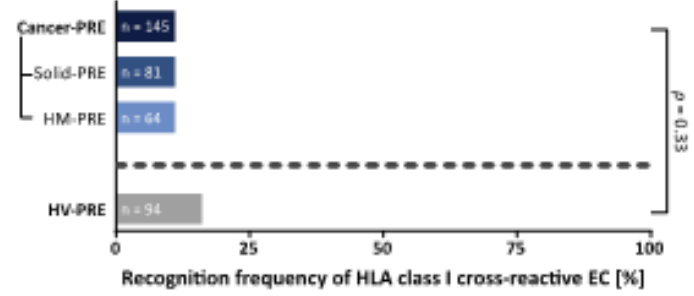

E

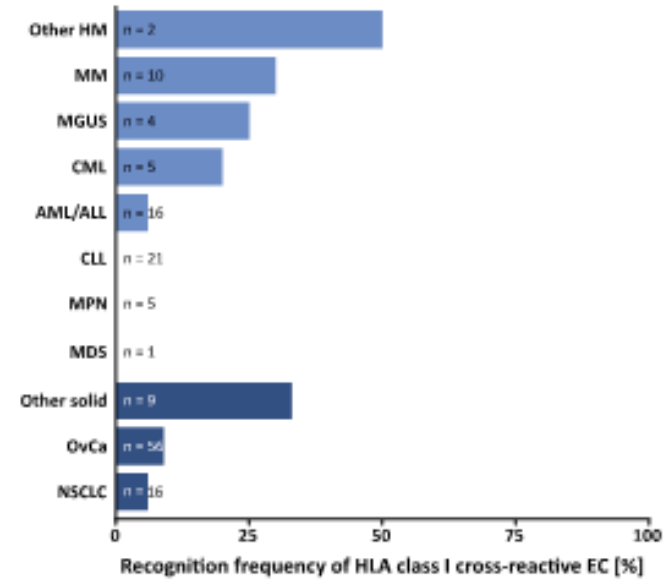

G

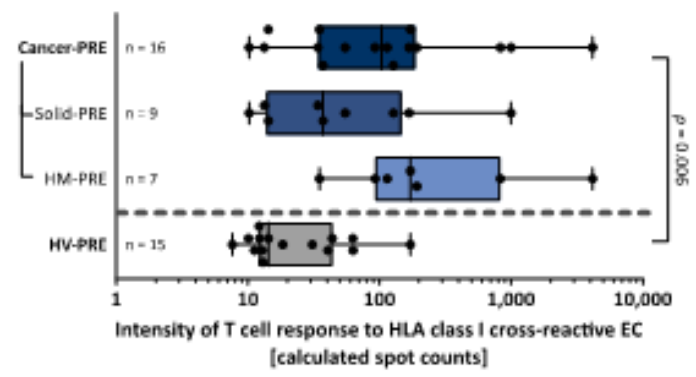

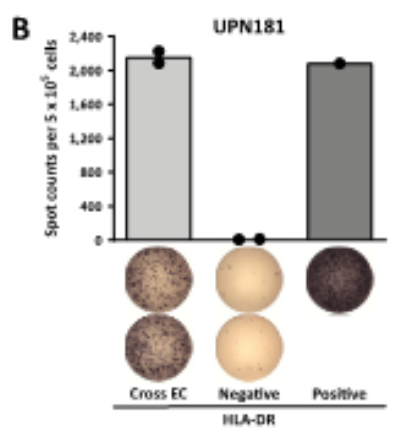

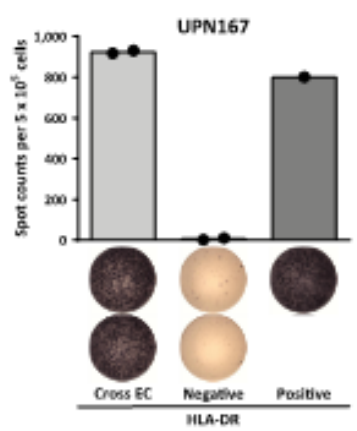

D

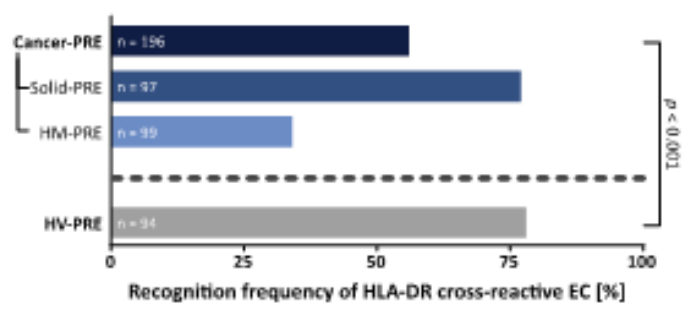

F

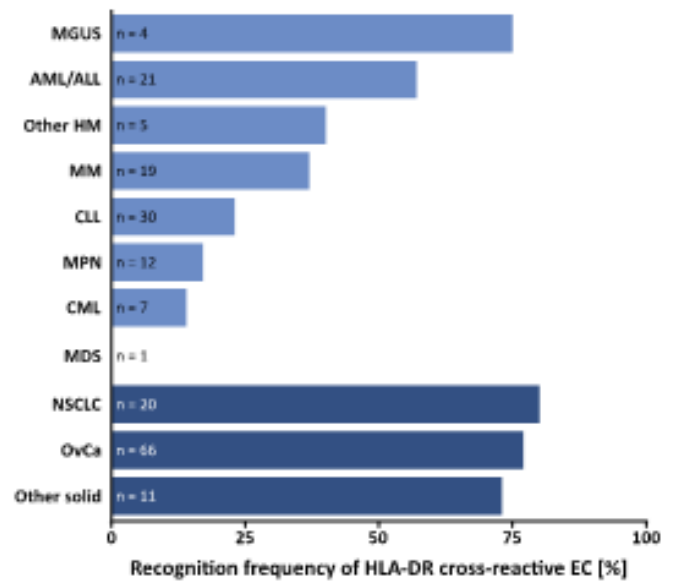

H

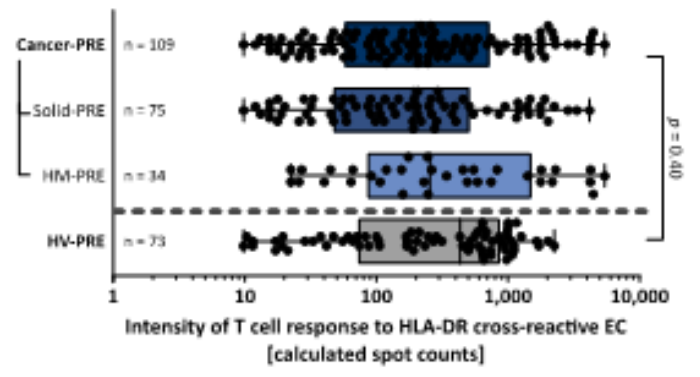

Figure 1

Cross-reactive SARS-CoV-2 T cell responses in unexposed cancer patients (cancer-PRE). (A,B) Exemplary IFN- $\gamma$ ELISPOT assays of PBMCs from pre-pandemic cancer patients after 12-day in vitro expansion with crossreactive (A) HLA class I and (B) HLA-DR epitope compositions (EC). T cell responses were considered positive when the mean spot count was $\geq 3$-fold higher than the respective negative control. Data are presented as scatter dot plot with mean. (C-F) Recognition frequencies of cross-reactive (C,E) HLA class I and (D,F) HLA-DR EC in unexposed cancer patients with solid-PRE and hematological malignancies (HM-PRE) compared to healthy volunteers (HV-PRE, two-sided Fisher's exact test). (G-H) Intensities (calculated spot counts) of T cell responses to cross-reactive $(\mathrm{G})$ HLA class I and $(\mathrm{H})$ HLA-DR EC in unexposed cancer-PRE patients and HV-PRE. Data shown for donors with detectable $T$ cell responses; boxes represent median and 25th to 75th percentiles, whiskers are 
minimum to maximum, two-sided Mann-Whitney U-test. Abbreviations: UPN, uniform patient number; cross EC, cross-reactive epitope composition; HM, hematological malignancies; $A L L$, acute lymphoblastic leukemia; $A M L$, acute myeloid leukemia; CLL, chronic lymphocytic leukemia; CML, chronic myeloid leukemia; MDS, myelodysplastic syndrome; MM, multiple myeloma; MGUS, monoclonal gammopathy of undetermined significance; MPN, myeloproliferative neoplasm; NSCLC, non-small cell lung cancer; OvCa, ovarian carcinoma.

A

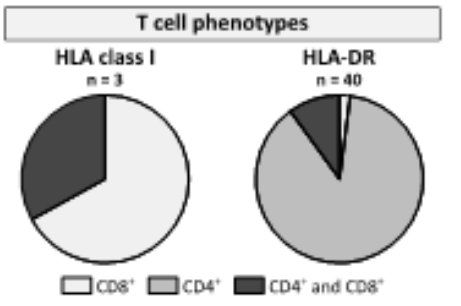

B

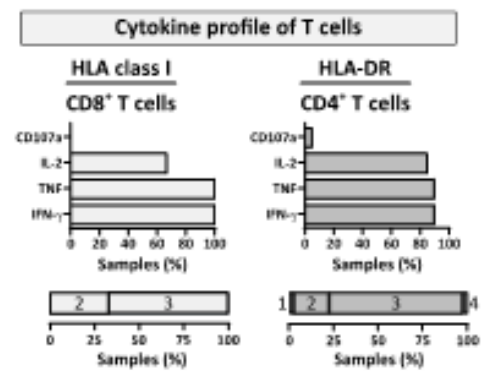

c
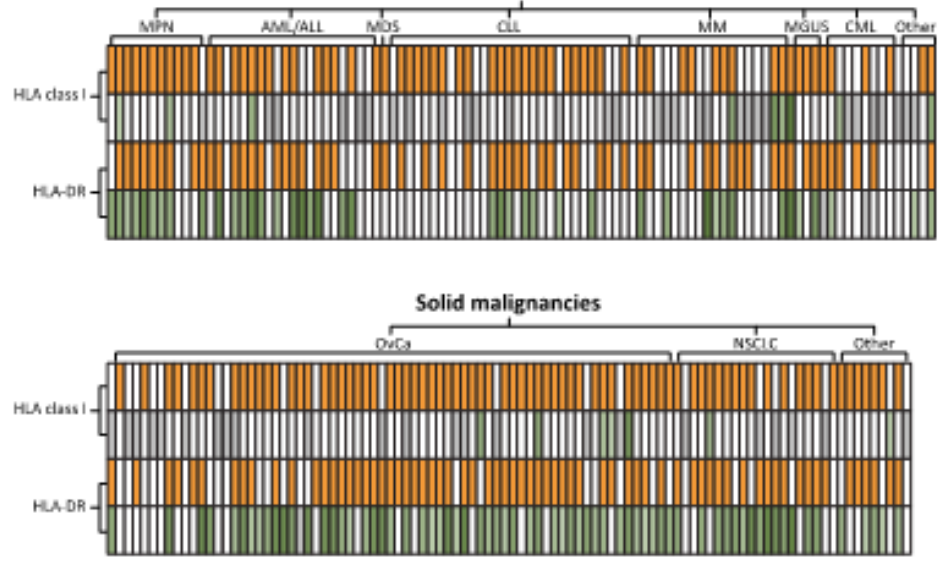

Viral peptide panel $\square$ T cell response $\square$ No T cell response
Cross-reactive EC (mean calculated spot count)
$\square$ Not asailsble $\square^{\text {No T cell response }} \square^{\text {T cell responce }}$
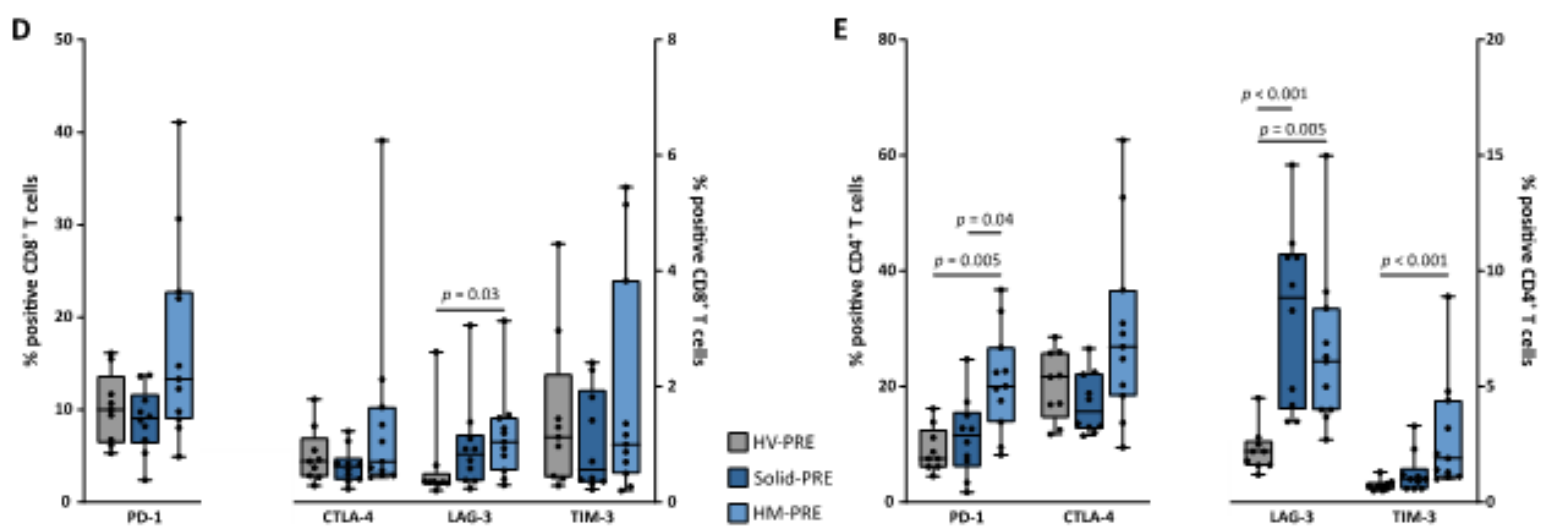

Figure 2

Characterization of SARS-CoV-2 T cell phenotypes and general T cell functionality in unexposed cancer-PRE patients. ( $A$ and $B$ ) Flow cytometry-based characterization of $(A)$ phenotypes and $(B)$ cytokine profiles of crossreactive $T$ cell responses to HLA class I (left panels) and HLA-DR EC (right panels) using T cells from unexposed cancer patients after 12-day in vitro expansion. (B) Cytokine profiles (IFN- $\gamma$, TNF, IL-2) and degranulation marker (CD107a) expression of CD8+ (left panel) and CD4+ T cells (right panel). Percentage of samples with CD107a+, IL-2+, TNF+, and IFN- $y+$ T cell responses are shown in the upper rows. The lower rows display the proportion of samples revealing mono- (1), di- (2), tri- (3), or tetra-functional (4) T cell responses. (C) Heatmap of recognition frequency and intensity (color gradient green) of T cell responses to cross-reactive SARS-CoV-2 HLA class I and HLA DR EC in comparison to the recognition frequency of HLA class I and HLA-DR viral peptide panels (orange) comprising e.g. Epstein-Barr virus (EBV), cytomegalovirus (CMV), and adenovirus (ADV) peptides in unexposed cancer patients (total $n=199$; upper panel hematological malignancies $n=101$; lower panel solid malignancies $n=98$ ). (D and E) Flow cytometry-based analysis of T cell exhaustion marker expression (PD-1, CTLA-4, LAG-3, TIM 3) in (D) CD8+ and (E) CD4+ T cells of SARS-CoV-2 unexposed cancer patients (solid-PRE $n=10, H M-P R E ~ n$ 
= 11) and healthy volunteers (HV-PRE, $n=9)$. HV-PRE, solid-PRE, and HM-PRE are depicted in grey, dark blue, and light blue, respectively. Boxes represent median and 25th to 75th percentiles, whiskers are minimum to maximum, Kruskal-Wallis test, p adjusted with Dunn's multiple comparisons test.

A

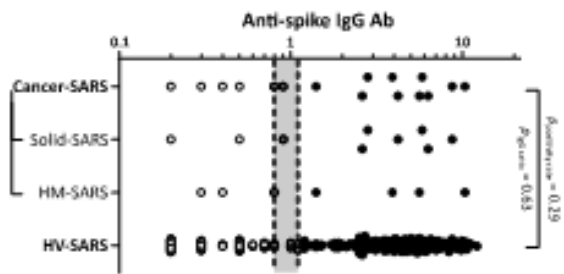

B

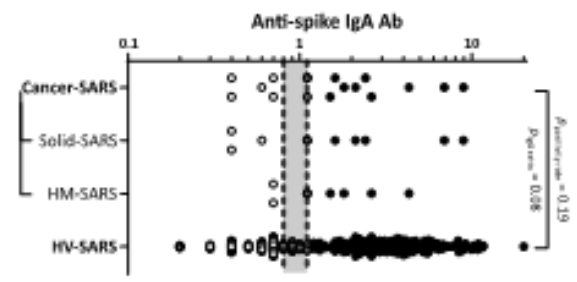

C

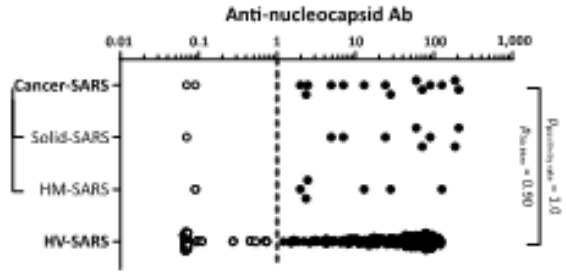

F

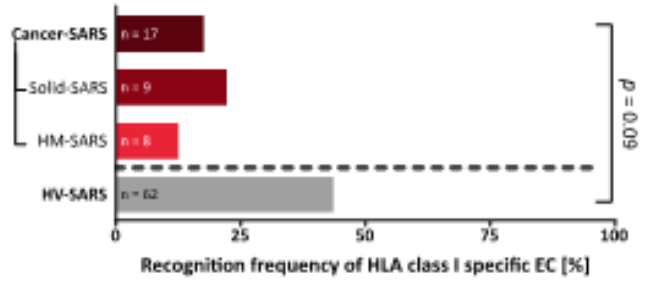

H

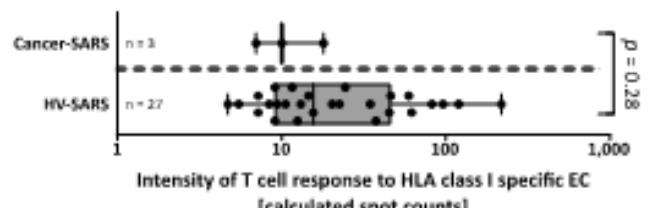

[calculated spot counts]
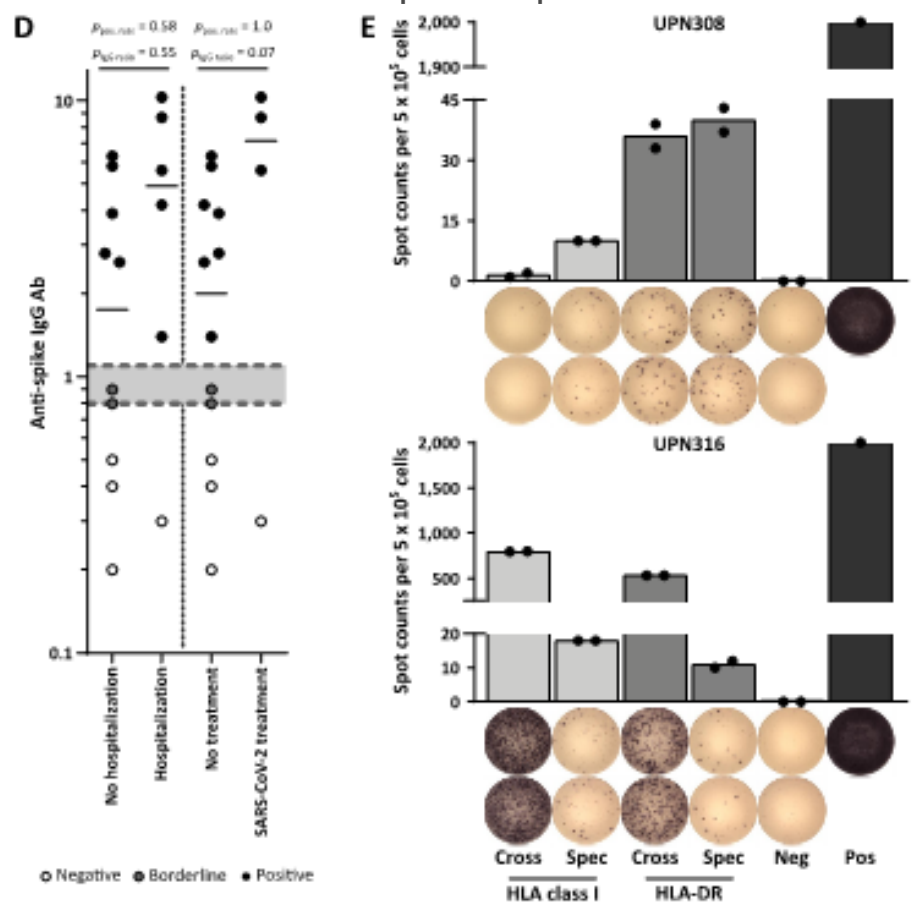

G

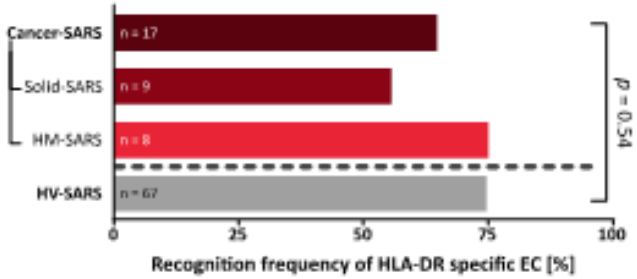

I

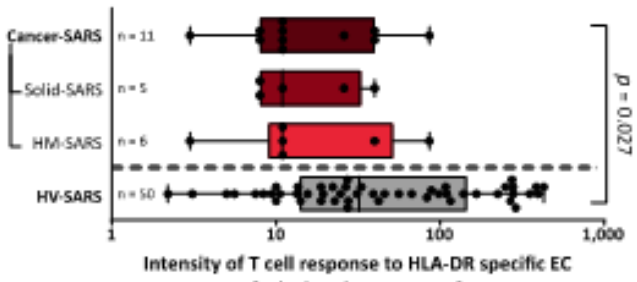

[calculated spot counts]

\section{Figure 3}

Antibody and T cell responses to SARS-CoV-2 in COVID-19 cancer patients (cancer-SARS). (A-D) SARS-CoV-2directed antibody responses in cancer-SARS and healthy volunteers (HV-SARS) after SARS-CoV-2 infection. SARS-CoV-2 serum anti-spike (A) IgG and (B) IgA S1 ratios (EUROIMMUN) as well as (C) anti-nucleocapsid antibody titers (Elecsys immunoassay). (D) Anti-spike IgG ratios (EUROIMMUN) of cancer-SARS grouped by severity of COVID-19 (requiring hospitalization or SARS-CoV-2-specific treatment; Fisher's exact test for positivity rate, Mann-Whitney U-Test for antibody ratios/titers of positive patients). Donors with negative and borderline responses are marked in white and grey, respectively. (E) Exemplary ex vivo IFN-y ELISPOT assays using T cells from two cancer-SARS patients stimulated with cross-reactive or SARS-CoV-2-specific HLA class I and HLA-DR epitope compositions. T cell responses were considered positive when the mean spot count was $\geq 3$ fold higher than the negative control. ( $F$ and G) Recognition frequencies of SARS-CoV-2-specific (F) HLA class I and (G) 
HLA-DR EC in cancer-SARS patients and healthy volunteers (HV-SARS, two-sided Fisher's exact test). (H and I) Intensities (calculated spot counts) of T cell responses to SARS-CoV-2-specific (H) HLA class I and (I) HLA-DR EC in cancer-SARS and HV-SARS. Data shown for donors with T cell responses; boxes represent median and 25th to 75th percentiles, whiskers are minimum to maximum, two-sided Mann-Whitney U-test. Abbreviations: pos. rate, positivity rate; UPN, uniform patient number; cross, cross-reactive EC; spec, SARS-CoV-2-specific EC; neg, negative control; pos, positive control.
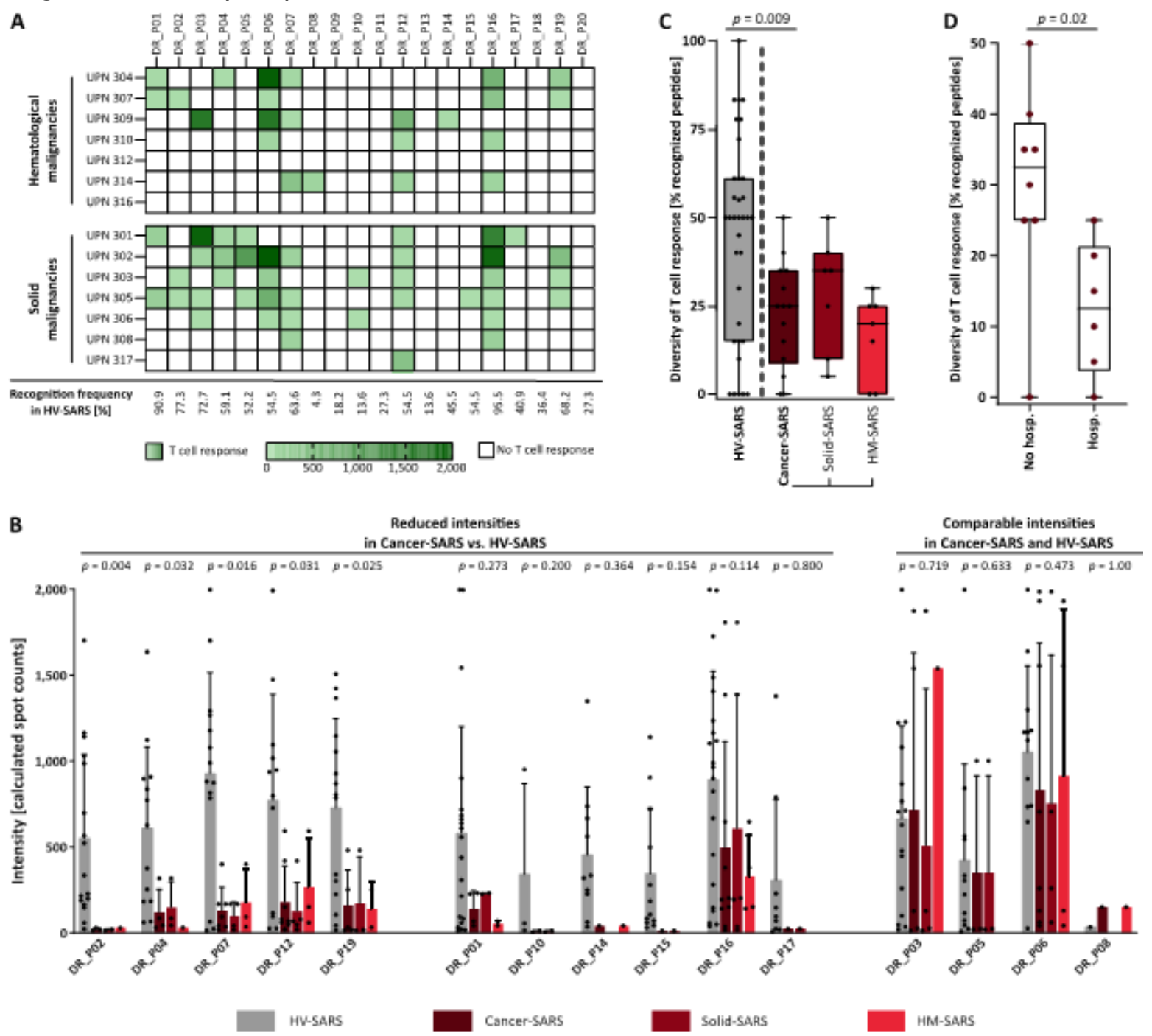

Figure 4

Diversity and intensity of SARS-CoV-2 T cell responses to single HLA-DR epitopes in cancer-SARS patients. (A) Heatmap of recognition frequencies and intensities (calculated spot count, color gradient green) of SARS-CoV-2 T cells to single SARS-CoV-2-derived HLA-DR T cell epitopes in IFN- $\gamma$ ELISPOT assays after 12-day in vitro expansion using PBMCs from cancer-SARS patients ( $n=14$ ) with hematological (upper panel, HM-SARS, $n=7$ ) and solid tumors (lower panel, solid-SARS, $n=7$ ). Recognition frequencies of the respective HLA DR T cell epitopes in COVID-19 convalescent healthy volunteers (HV-SARS, $n=34$ ) in IFN- $y$ ELISPOT assays after 12-day in vitro expansion are listed below. (B) Intensities of T cell responses against individual HLA-DR SARS-CoV-2 T cell epitopes in cancer-SARS $(n=14)$ and HV-SARS $(n=34)$ after SARS-CoV-2 infection. Data shown for donors with T cell responses; mean with SD (error bars). (C) Diversity of SARS-CoV-2 HLA-DR T cell responses (recognized peptides/tested peptides) in cancer patients ( $n=14$; HM-SARS $n=7$; solid-SARS $n=7$ ) and HV- 
SARS ( $n=34$ ) after SARS-CoV-2 infection as assessed in IFN-y ELISPOT assays after 12-day in vitro expansion; boxes represent median and 25th to 75th percentiles, whiskers are minimum to maximum, two-sided MannWhitney U-test. (D) Diversity of SARS-CoV-2 HLA-DR T cell responses (recognized peptides/tested peptides) in hospitalized ( $n=8)$ vs. non-hospitalized cancer patients $(n=8)$; boxes represent median and 25th to 75th percentiles, whiskers are minimum to maximum, two-sided Mann-Whitney U-test. Abbreviations: UPN, uniform patient number; no hosp., no hospitalization; hosp., hospitalization.

\section{Supplementary Files}

This is a list of supplementary files associated with this preprint. Click to download.

- Supplement.pdf 